\title{
COMPARISON OF MICRONIZED PROGESTERONE (CYCLOGEST PESSARY) AND PLACEBO IN PREVENTION OF PRE-TERM BIRTH IN TERTIARY CARE HOSPITAL
}

\author{
Nighat Afridi, Ambreen Fatima*, Amna Fareed**, Saifullah Khan**, Shah Gul Khan*** \\ Combined Military Hospital Nowshera/National University of Medical Sciences (NUMS) Pakistan, *Fauji Foundation Hospital, Rawalpindi \\ Pakistan, ${ }^{* *}$ Muhammad College of Medicine, Peshawar Pakistan, ${ }^{* * *}$ Aga Khan University, Karachi Pakistan, ${ }^{* * * * K h y b e r ~ M e d i c a l ~ C o l l e g e, ~}$ \\ Peshawar Pakistan
}

\begin{abstract}
Objective: To compare efficacy of micronized per rectal progesterone (cyclogest pessary) and placebo in prevention of preterm birth in tertiary care hospital.

Study Design: Randomized controlled trial (RCT).

Place and Duration of Study: Study was conducted at department of gynecology and Obstetrics, Combined Military Hospital Nowshera, Khyber Pakhtunkhwa, from Jan 2018 to Jun 2018.

Methodology: A sample size of 140 patients was calculated using WHO calculator. Non probability consecutive sampling was used for recruitment of participants. Ethics approval and consent forms were taken. Women were divided into two groups randomly. Group A was given micronized progesterone (cyclogest pessary) per rectal usage and group B was given placebo. Patients were followed for maternal and neonatal outcomes. Data was analyzed using SPSS version 23 . Independent t-test was applied. $p$-value $\leq 0.05$ was considered significant.

Results: Total 140 patients were included in study. Mean age of women was 29.4 years $\pm 4.6 \mathrm{SD}$. Patients in micronized progesterone (cyclogest pessary) was more effective in increasing birth weight $(p=0.00)$, Apgar score maintenance at $1^{\text {st }}(p=0.00)$ and $5^{\text {th }}$ minute $(p=0.000)$ and reduction in length of hospital stay $(p=0.000)$ as compared to placebo. Patients were more satisfied with micronized progesterone (cyclogest pessary) per rectal as compared to placebo $(p=0.00)$.

Conclusion: Preterm birth is remained as significant issue in health care system of Pakistan. However, micronized progesterone (cyclogest pessary) per rectal usage had positive impact in improving maternal and neonatal health outcomes. Effective strategies for prevention of preterm birth in Pakistan are required.
\end{abstract}

Keywords: Cyclogest pessary, Preterm birth, Progesterone.

This is an Open Access article distributed under the terms of the Creative Commons Attribution License (http://creativecommons.org/licenses/by/4.0), which permits unrestricted use, distribution, and reproduction in any medium, provided the original work is properly cited.

\section{INTRODUCTION}

Preterm birth is leading cause of death under five years of children, globally ${ }^{1}$. An estimated 15 million preterm babies born per year, Worldwide $^{2}$. According to World Health Organization (WHO), one million children die each year due to preterm birth complications. Preterm birth is defined as birth (alive) before 37 weeks of pregnancy. WHO divided preterm birth into three categories; extremely preterm ( $<28$ weeks), very preterm (28-37 weeks) and moderate to late pre term (32-37 weeks) ${ }^{3}$. Africa and South Asia are suffering with more than $60 \%$ preterm births 4 . Prevalence of preterm birth is $12 \%$ in low income

Correspondence: Dr Nighat Afridi, Head of Gynaecology \& Obstetrics Department, CMH Nowshera Pakistan

Received: 15 Feb 2019; revised received: 02 May 2020; accepted: 25 Nov 2020 countries and $9 \%$ in high income countries 5 . Pakistan is ranked $4^{\text {th }}$ in latest global listing of preterm births (750000 preterm births in 2010) ${ }^{6}$.

An estimated weekly cost of preterm birth is 10000 U.S dollars, in United States in 19907. However, recent literature suggests annual cost of preterm birth is 26 billion U.S dollars. Moreover, the cost is increasing with earlier gestational ages ${ }^{8}$. The cause of preterm birth is multifactorial (with social, biological, psychological factors playing significant role). Most common risk factor for preterm birth is previous history of preterm birth 9 .

Progesterone had significant role in prevention of preterm birth through anti inflammatory properties. Progesterone is associated with raising possible links between inflammatory 
processes leading towards progesterone receptor expression alteration and preterm labor onset ${ }^{10}$. Pharmacokinetics of progesterone is associated with its use in menopausal, assisted reproduction, use in post menopausal women, and endometrial carcinoma. Pharmacokinetics of progesterone is dependent upon route of administration. Literature reported that per rectal or vaginal use is more effective than oral administration ${ }^{11}$.

Literature reported that vaginal pessaries are more effective in prevention of preterm birth as compared to placebo (RR: 1.95 , C.I: $95 \%$ and $p=0.00$ ). However, progesterone use is associated with antenatal tocolysis reduction ${ }^{12}$. Another similar study reported that intramuscular and per rectal progesterone usage is effective in preterm birth prevention as compare to oral progesterone $(p=0.01)^{13}$. Limited data is available on per rectal usage of progesterone in Pakistani settings. Present study aims to compare efficacy of micronized per rectal progesterone (cyclogest pessary) and placebo in prevention of preterm birth in tertiary care hospital.

\section{METHODOLOGY}

A randomized controlled trial was conducted at department of Gynaecology and Obstetrics, Combined Military Hospital Nowshera KPK, from January 2018 to June 2018. Ethical approval was taken from ethics review board. Consent forms were taken from all participants. A sample size of 140 patients was calculated with $5 \%$ level of significance, $80 \%$ power of study, $\mathrm{P} 1=95.5 \%$, $\mathrm{P} 2=80 \%$ and absolute precision $5 \%$ using $\mathrm{WHO}$ calculator ${ }^{14}$. Non probability consecutive sampling was used for recruitment of participants. Inclusion criteria include women in reproductive age (20-45 years), minimum two C-section previously resulting in preterm birth, short cervical length on anomaly scan ranging from $2.5 \mathrm{~cm}$ to $3 \mathrm{~cm}$ and history of prolonged nursery stay. Patients with abnormal fetuses, multiple gestations, uterine malformation and patients with cervical cerclage were excluded. Patients were divided into two groups using computer generated random number table. Group A was given micronized progesterone per rectal (cyclogest pessary) $400 \mathrm{mg}$ daily while group B was given oral multivitamins (Placebo). Patients were undergone through following test urine culture and sensitivity test, high vaginal swabs and C-reactive proteins (CRP) blood test. All patients were delivered before 37 weeks. Primary outcomes of study were mean gestational age, rate of pre term delivery and time of delivery in both groups. Secondary outcomes include infant (birth weight, Apgar score at 1st and 5th minute, length of hospital stay) maternal (adverse effects of drugs and patients satisfaction with drugs). Data was analyzed using SPSS version 23. Quantitative (Mean \pm standard deviation) and qualitative (frequency and percentage) were analyzed. Independent $\mathrm{t}$-test was applied. $p$-value $\leq 0.05$ was considered significant.

\section{RESULTS}

Total 140 patients were included in study with 1:1 randomization (70 patients in each group). Mean age of women was 29.4 years \pm 4.6 SD. Mean Body mass index (BMI) was $30.5 \mathrm{~kg} / \mathrm{m}$ $2 \pm 3$ SD. Mean number of previous pregnancies were $2.8 \pm 0.7 \mathrm{SD}$. Mean Number of previous preterm deliveries was $2.9 \pm 0.9$ SD. Mean length of cervix was $21.5 \mathrm{~mm} \pm 0.92 \mathrm{SD}$. Mean gestational age at beginning of treatment was 15.8 weeks \pm 0.92 SD. Mean gestational age at delivery was 33.8 months \pm 1.7 SD. Mean birth weight of infants was 2491 grams \pm 2.7 SD. Mean Apgar score at 1 st minute was $7.1 \pm 1.3$ SD. Mean Apgar score at 5 th minute was $7.7 \pm 0.99$ SD. Mean length of hospital stay was 6.8 days $\pm 1.8 \mathrm{SD}$.

Mean age of mother was $29.08 \pm 4.7 \mathrm{SD}$ in cyclogest pessary group while $29.8 \pm 4.6 \mathrm{SD}$ in placebo group $(p=0.35)$. Mean BMI was $30.47 \pm$ 3.2 SD in cyclogest pessary group while $30.61 \pm$ $2.9 \mathrm{SD}$ in placebo group $(p=0.78)$. Mean number of previous pregnancies were $2.9 \pm 0.7 \mathrm{SD}$ while $2.7 \pm 0.7 \mathrm{SD}$ in placebo group $(p=0.100)$. Mean number of previous pre term deliveries were 3.1 $\pm 1.05 \mathrm{SD}$ and $2.6 \pm 0.6 \mathrm{SD}$ in placebo group $(p=0.002)$. Mean length of cervix was $21.5 \pm 0.91$ $\mathrm{SD}$ in cyclogest pessary group while $21.6 \pm 0.93$ 
SD in placebo group $(p=0.715)$. Mean gestational age at beginning of treatment was $15.9 \pm 0.95 \mathrm{SD}$ and 15.8 $\pm 0.90 \mathrm{SD}$ in placebo group $(p=0.650)$.

Mean birth weight was significantly high in progesterone (cyclogest pessary) $2583 \pm 2.2 \mathrm{SD}$ $(p=0.00)$. Mean length of hospital stay was significantly lower in progesterone (cyclogest pessary group) $5.7 \pm 0.7 \mathrm{SD}$ as compared to placebo $8.5 \pm$ 0.86 SD $(p=0.000)$. Patients in (cyclogest pessary) progesterone per rectal use were more satisfied

Table-I: Mother parameters in progesterone (cyclogest pessary) and placebo.

\begin{tabular}{|c|c|c|c|}
\hline \multirow[b]{2}{*}{ Mother Parameters } & \multicolumn{2}{|c|}{ Interventional Group } & \multirow[b]{2}{*}{$p$-value } \\
\hline & $\begin{array}{c}\text { Progesterone Cyclogest } \\
\text { Pessary }(\mathrm{N}=70)\end{array}$ & $\begin{array}{c}\text { Placebo } \\
(N=70)\end{array}$ & \\
\hline Age of mother & $29.08 \pm 4.7 \mathrm{SD}$ & $29.8 \pm 4.6 \mathrm{SD}$ & 0.35 \\
\hline Body Mass Index & $30.47 \pm 3.2 S D$ & $30.61 \pm 2.9 \mathrm{SD}$ & 0.78 \\
\hline No. of previous pregnancies & $2.9 \pm 0.7 \mathrm{SD}$ & $2.7 \pm 0.7 \mathrm{SD}$ & 0.100 \\
\hline No. of previous pre term deliveries & $3.1 \pm 1.05 S D$ & $2.6 \pm 0.6 \mathrm{SD}$ & 0.002 \\
\hline Length of cervix & $21.5 \pm 0.91 S D$ & $21.6 \pm 0.93 S D$ & 0.715 \\
\hline Gestational age at beginning of treatment & $15.9 \pm 0.95 S D$ & $15.8 \pm 0.90 S D$ & 0.650 \\
\hline \multicolumn{4}{|c|}{ Table-II: Infant outcome in both progesterone (cyclogest pessary) and placebo group. } \\
\hline \multirow[b]{2}{*}{ Infant Outcomes } & \multicolumn{2}{|c|}{ Interventional Group } & \multirow[b]{2}{*}{$p$-value } \\
\hline & $\begin{array}{c}\text { Progesterone Cyclogest } \\
\text { Pessary }(\mathrm{N}=70)\end{array}$ & $\begin{array}{c}\text { Placebo } \\
(\mathrm{N}=70)\end{array}$ & \\
\hline Birth weight & $2583 \pm 2.2 \mathrm{SD}$ & $2399 \pm 1.9 \mathrm{SD}$ & 0.000 \\
\hline Gestational age at delivery & $34 \pm 1.7 \mathrm{SD}$ & $33 \pm 1.7 \mathrm{SD}$ & 0.103 \\
\hline Apgar score at 1st minute & $5.9 \pm 0.67 \mathrm{SD}$ & $8.2 \pm 0.7 \mathrm{SD}$ & 0.000 \\
\hline Apgar score at 5 th minute & $6.9 \pm 0.6 \mathrm{SD}$ & $8.6 \pm 0.4 \mathrm{SD}$ & 0.000 \\
\hline Length of hospital stay & $5.7 \pm 0.7 \mathrm{SD}$ & $8.5 \pm 0.86 \mathrm{SD}$ & 0.000 \\
\hline
\end{tabular}

as compared to placebo $2399 \pm 1.9 \mathrm{SD}(p=0.000)$. Mean gestational age at delivery was 34 years \pm 1.7 SD in progesterone group while 33 years \pm 1.7 $\mathrm{SD}$ in placebo group $(p=0.103)$. Mean Apgar scores at 1st minute were significantly lower in progesterone (cyclogest pessary) group $5.9 \pm 0.67 \mathrm{SD}$

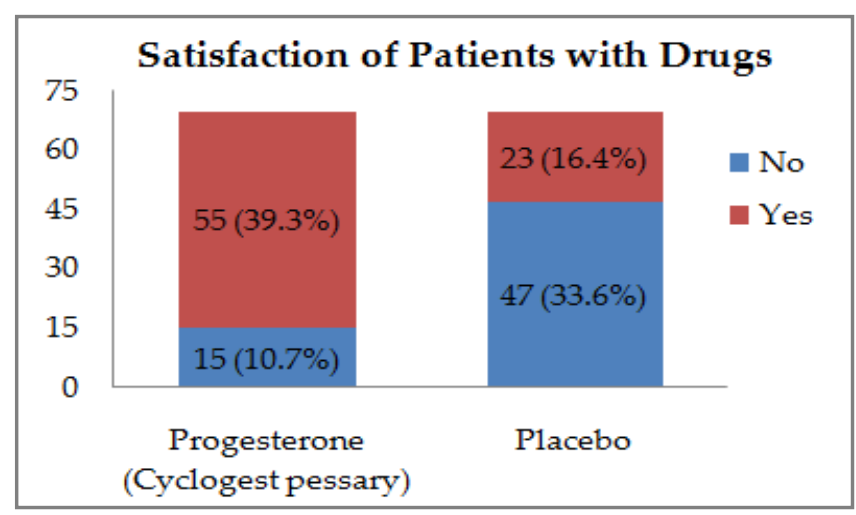

Figure-1: Satisfaction with interventional drugs.

as compared to placebo $8.2 \pm 0.7 \mathrm{SD}(p=0.00)$. Apgar scores at 5 minute were significantly lower in progesterone (cyclogest pessary) group 6.9 $\pm 0.6 \mathrm{SD}$ as compared to placebo $8.6 \pm 0.4 \mathrm{SD}$ than placebo, as shown in fig-1.

\section{DISCUSSION}

Preterm births had significant contribution in infant mortality and morbidity, worldwide. In present study, total 140 patients were included. Mean birth weight was significantly high in progesterone (cyclogest pessary) $2583 \pm 2.2 \mathrm{SD}$ as compared to placebo $2399 \pm 1.9 \mathrm{SD}(p=0.000)$. Mattisonet al reported that birth weight in infants after preterm delivery is significantly increased with progesterone dose during pregnancy $(p=$ $0.01)^{15}$. Another similar study reported that female infants were more weighed as compared to males when mothers were treated with oral progesterone in pregnancy $(45 \% \text { vs } 20 \%, p=0.05)^{16}$.

In present study, Mean Apgar scores at $1^{\text {st }}$ minute were significantly lower in progesterone (cyclogest pessary) group $5.9 \pm 0.67 \mathrm{SD}$ as compared to placebo $8.2 \pm 0.7 \mathrm{SD}(p=0.00)$. Hack et $a l$, reported no significant difference in Apgar scores of oral progesterone and placebo was found $(p>0.05)^{17}$. However, Allen et al, found out 
that vaginal progesterone used during pregnancy had significantly reduced Apgar scores after birth $(p=0.00)^{18}$.

In present study, Apgar scores at 5 minute were significantly lower in progesterone (cyclogest pessary) group $6.9 \pm 0.6 \mathrm{SD}$ as compared to placebo $8.6 \pm 0.4 \mathrm{SD}(p=0.00)$. Kilpatrick et al, reported that a positive correlation was found in apgar scores and progesterone used during pregnancy $(r=0.9)^{19}$.

In present study, mean length of hospital stay was significantly lower in progesterone (cyclogest pessary group) $5.7 \pm 0.7 \mathrm{SD}$ as compared to placebo $8.5 \pm 0.86 \mathrm{SD}(p=0.000)$. Elder et al, reported that length of NICU admissions was significantly lower in per rectal progesterone group as compared to vaginal group ${ }^{20}$. Moreover, Petrou et al reported that mean hospital stay is significantly high in placebo as compare to oral progesterone (RR; $1.7,95 \% \mathrm{CI} ; p=0.01)^{21}$.

In present study, patients in cyclogest pessary progesterone per rectal use were more satisfied than placebo $(p=0.00)$. Hack et al, reported that patients were more satisfied with oral progesterone as compare to vaginal progesterone $(p=0.01)^{22}$. Another similar study reported that more satisfaction with rectal usage of progesterone was reported in women as compared to vaginal $(p=0.02)^{23}$.

\section{LIMITATION OF STUDY}

Study conducted at single center limits generalizability of study.

\section{CONCLUSION}

Preterm birth remained as significant issue in health care system of Pakistan. However, progesterone (cyclogest pessary) per rectal usage had positive impact in improving maternal and neonatal health outcomes. Effective strategies for prevention of preterm birth in Pakistan are required.

\section{CONFLICT OF INTEREST}

This study has no conflict of interest to be declared by any author.

\section{REFERENCES}

1. Illar J, Abalos E, Carroli G, Giordano D, Wojdyla D, Piaggio G, et al. Heterogeneity of perinatal outcomes in the preterm delivery syndrome. Obstet Gynecol 2014; 104(2): 78-87.

2. Saigal S, Szatmari P, Rosenbaum P, Campbell D, King S. Cognitive abilities and school performance of extremely low birthweight children and matched term control children at age 8 years: a regional study. J Pediatr 2014; 118(2): 751-60.

3. Steer P. The epidemiology of preterm labour. Br J Obstet Gynaecol 2015; 112(1): 1-3.

4. Wen SW, Smith G, Yang Q, Walker M. Epidemiology of preterm birth and neonatal outcome. Semin Fetal Neonatal Med 2014; 9(6): 429-35.

5. Kuehn BM. Groups take aim at US preterm birth rate. J Am Med Assoc 2016; 296(3): 2907-08.

6. Langhoff-Roos J, Kesmodel U, Jacobsson B, Rasmussen S, Vogel I. Spontaneous preterm delivery in primiparous women at low risk in Denmark: population based study. Br Med J 2016; 332(4): 937-39.

7. Tracy SK, Tracy MB, Dean J, Laws PJ, Sullivan EA. Spontaneous preterm birth of liveborn infants in women at low risk in Australia over 10 years: a population-based study. Br J Obstet Gynaecol 2017; 114(4): 731-35.

8. Blondel B, Macfarlane A, Gissler M, Breart G, Zeitlin J. Groupft PS Preterm birth and multiple pregnancy in European countries participating in the PERISTAT project. Br J Obstet Gynaecol 2016; 113(3): 528-35.

9. Smith GC, Shah I, Pell JP, Crossley JA, Dobbie R. Maternal obesity in early pregnancy and risk of spontaneous and elective preterm deliveries: a retrospective cohort study. Am J Public Health 2017; 97(3): 157-62.

10. Martin JA, Hamilton BE, Sutton PD, Ventura SJ, Menacker F, Kirmeyer S. Births: Final Data for 2004. Natl Vital Stat Rep 2016; 55(3): 1-140.

11. Burguet A, Kaminski M, Abraham-Lerat L, Schaal JP, Cambonie G, Fresson J, et al. The complex relationship between smoking in pregnancy and very preterm delivery. Results of the Epipage study. Br J Obstet Gynaecol 2014; 111(5): 258-65.

12. European community collaborative study of outcome of pregnancy between 22 and 28 weeks gestation. Working group on the very low birthweight infant. Lancet 2015; 336(3): 782-84.

13. Chan K, Ohlsson A, Synnes A, Lee DSC, Chien L, Lee SK, et al. Survival, morbidity, and resource use of infants of 25 weeks gestational age or less. Am J Obstet Gynecol 2014; 185(4): 220-26.

14. Kramer MS, Demissie K, Yang H, Platt RW, Sauve R, Liston R. The contribution of mild and moderate preterm birth to infant mortality. Fetal and infant health study group of the Canadian perinatal surveillance system. J Am Med Assoc 2013; 284(3): 843-49.

15. Mattison DR, Damus K, Fiore E, Petrini J, Alter C. Preterm delivery: a public health perspective. Paediatric Perinatal Epidemiol 2015; 15(2): 7-16.

16. Lefebvre F, Glorieux J, St Laurent-Gagnon T. Neonatal survival and disability rate at age 18 months for infants born between 23 and 28 weeks of gestation. Am J Obstet Gynecol 2016; 174(4): 833-38.

17. Hack M, Friedman H, Fanaroff AA. Outcome of extremely low birthweight infants. Pediatr 2016; 98(3): 931-37.

18. Allen MC, Donohue PK, Dusman AE. The limit of viabilityneonatal outcome of infants born at 22 to 25 weeks gestation. N Engl J Med 2016; 329(3): 1597-01. 
19. Kilpatrick SJ, Schleuter MA, Piecuch RE, Leonard CH, Rogido $\mathrm{M}$, Sola A. Outcome of infants born at 24-26 weeks gestation: I. survival and cost. Obstet Gynecol 2014; 90(4): 803-08.

20. Elder DE, Hagan R, Evans SF, Benninger HR, French NP. Hospital admissions in the first year of life in very preterm infants. J Paediatr Child Health 2016; 35(2): 145-50.
21. Petrou S, Mehta Z, Hockley C, Cook-Mozaffari P, Henderson J, Goldacre M. The impact of preterm birth on hospital inpatient admissions and costs during the first 5 years of life. Pediatri 2016; 112(4): 1290-97.

22. Hack M, Fanaroff A. Outcome of extremely low birthweight and gestational age in the 1990s. Early Hum Dev 2015; 53(4): 193-18. 